\title{
Hearing impairment among Korean farmers, based on a 3-year audiometry examination
}

\author{
Sujin Lee ${ }^{1, C-D \oplus}$, Kyungsuk Lee ${ }^{2, A \oplus}$, Soo-Jin Lee,A-B,F® \\ ${ }^{1}$ Department of Occupational and Environmental Medicine, College of Medicine, Hanyang University, Korea \\ ${ }^{2}$ Agricultural Safety Engineering Division, National Academy of Agricultural Science, Rural Development Administration, \\ Korea \\ A - Research concept and design, B - Collection and/or assembly of data, C - Data analysis and interpretation, \\ $D$ - Writing the article, E-Critical revision of the article, F- Final approval of article
}

Sujin Lee, Kyungsuk Lee, Soo-Jin Lee. Hearing impairment among Korean farmers, based on a 3-year audiometry examination. Ann Agric Environ Med. 2019; 26(1): 148-153. doi: 10.26444/aaem/102292

\begin{abstract}
Introduction and objective. Work noise exposure among farmers can cause hearing loss. Farmers are exposed to hazardous noise from equipment and domestic animals, and experience high rates of noise-induced hearing loss. The aim of our study was to evaluate the hearing thresholds of farmers in Korea. This study is the first to evaluate hearing impairment in Korean farmers nationwide. There have been few studies that have performed audiometric testing to measure hearing impairment at the national level in Korea.

Materials and method. Through the Farm Work Safety Model Project among the 40 villages in which inhabitants received health check-ups from 2006-2008, 2,027 people from 35 villages were targeted (957 people in 16 villages in 2006, 436 people in five villages in 2007, and 634 people in 14 villages in 2008) and underwent pure tone audiometry tests. 2,027 people from 35 villages underwent pure tone audiometry tests through the Farm Work Safety Model Project. The tests were conducted using a portable audiometer, and air conduction thresholds were determined.

Results. Hearing impairment at $3 \mathrm{kHz}$ and above was more prevalent in men than in women. The prevalence of moderateto-profound hearing impairment was $19.6 \%$ in the total study population and increased with age.

Conclusions. It is proposed that the high prevalence rate of farmers' hearing impairment may be due to excessive workplace noise. To manage farmers' hearing health, precise evaluations of farmers' hearing acuity and noise exposure on farms should be conducted. This study might be a stepping-stone to protect farmers' hearing health.
\end{abstract}

\section{Key words}

agriculture, sensorineural hearing loss, audiometry

\section{INTRODUCTION}

Agricultural work has numerous risks [1]. In the United States and Canada, farming continues to be one of the most dangerous occupations [2]. In South Korea, injuries from farming are increasing because of the decreasing agricultural population and increasing age of the work force [3]. Among the dangers faced by farmers, noise exposure can cause hearing loss. Farmers are exposed to hazardous noise from equipment and livestock and experience high rates of noiseinduced hearing loss (NIHL) [4]. Hearing loss due to noise in the agricultural industry has only recently attracted the attention of researchers, particularly those in the occupational research arena [5]. Hearing loss in farmers starts at a young age, occurs at higher frequencies, and increases with age and number of years exposed to farm noise [6]. When compared with national data, young people on farms had a higher prevalence of hearing loss. The high-frequency range of hearing was most affected, particularly at $6 \mathrm{kHz}$, and in the United States nearly 50\% of farm youths exhibited some degree of hearing loss [7].

Sensorineural hearing loss (SNHL) is primarily influenced by age, gender, and noise exposure [8]. NIHL is one of the most reported occupational diseases internationally [9]. Excessive

Address for correspondence: Soo-Jin Lee, Department of Occupational and Environmental Medicine, College of Medicine, Hanyang University, Korea e-mail: sjlee@hanyang.ac.kr

Received: 22.10.2018; accepted: 22.12.2018; first published: 29.01.2019 noise attributes to $37 \%$ of all adult causes of hearing loss and remains a significant contributor to employment-related morbidity internationally [10]. In Korea, NIHL is a common occupational disease, second only to pneumoconiosis. Mining, the armed forces, manufacturing, construction work, aeronautics, engineering and labouring, and farming are professions associated with increased exposure to occupational noise-induced hearing loss (ONIHL) [11]. Among American industries, the agriculture industry has the third largest number of potential noise-exposed employees [4]. ONIHL progresses with continued exposure to noise [4], is permanent, and may cause significant disability. Currently, although there is no known cure for ONIHL, it is largely preventable [10].

\section{OBJECTIVES}

Korean agriculture involves various risks of disease and farming accidents due to an increase in the age of farmers and the labour intensity required. In 2006, the Farm Work Safety Model Project was implemented by the Rural Development Administration to assess the risks and to improve the safety and health of farmers. For residents of selected villages, annual health check-ups have been implemented, including evaluation of hearing levels with pure tone audiometry, over a 3 year period. Based on the results of the pure tone audiometry, the current study evaluated hearing levels in order to assess the safety and health of Korean farmers. 


\section{MATERIALS AND METHOD}

Study participants. In 2006-2008, through the Farm Work Safety Model Project, among the 40 villages in which inhabitants received health check-ups, 2,027 people from 35 villages were targeted ( 957 people in 16 villages in 2006,436 people in five villages in 2007, and 634 people in 14 villages in 2008) and underwent pure tone audiometry tests. The villages are located across the country, in Gyeonggi-do, Gangwon-do, Chungcheong-do, Jeolla-do, Gyeongsang-do Provinces. A standardized interview included questions about demographic and socio-economic characteristics, including gender, age, years of farm work, principal farm commodity, education level, smoking habit, alcohol consumption, and previous and current diseases. There were 6 cases of ear disease diagnosed by a physician and were excluded from further analyses. All participants consented to using their personal information and clinical records for this study. IRB approval was not obtained because it was not obligatory when the study was performed.

Audiometric measurement. Pure-tone audiometry tests were conducted by using a portable audiometer (Voyager 522; Madsen Electronics; 5600 Rowland Rd \#275, Minnetonka, $\mathrm{MN}$, USA). The tests were performed in each village in a quiet room, without factory or nearby traffic noise, or other types of significant noise sources. Doctors were trained to operate the audiometer and then determined the hearing thresholds based on the results. Only air conduction thresholds were obtained. Participants pushed a button if they heard a tone. The frequencies tested were $0.5,1,2,3,4$, and $6 \mathrm{kHz}$.

Hearing impairment was categorized according to severity. Hearing impairment defined as a pure tone hearing threshold level $\geq 30$ decibels $(\mathrm{dB})$ at each $0.5,1,2,3,4$, and $6 \mathrm{kHz}$ for each ear. Moderate-to-profound hearing impairment was defined as a threshold $\geq 50 \mathrm{~dB}$ at $4 \mathrm{kHz}$ and an average of the thresholds at $0.5,1$, and $2 \mathrm{kHz} \geq 30 \mathrm{~dB}$.

Statistical analyses. To analyze the audiometric thresholds at each frequency by gender and age group, analysis of variance (ANOVA) was used. Differences in the prevalence of hearing impairments between men and women were analyzed using an independent t-test. Chi-square test was performed to compare the prevalence of moderate-to-profound hearing impairments according to age group within each gender. To determine if there were differences in mean age or years of farm work between the normal hearing and the moderate-to-profound hearing impairment group, t-tests and logistic regressions were performed. Statistical analyses were performed using SAS 9.4 (SAS Institute; Cary, NC) and SPSS (ver. 20.0; SPSS Inc., Chicago, IL, USA). All tests were 2 -sided, and p-values $<0.05$ were considered statistically significant.

\section{RESULTS}

A total of 2,027 subjects completed audiometric tests. The characteristics of the participants are presented in Table 1. The average age was $59.1( \pm 11.19)$ and average years of farm work $29.5( \pm 16.71)$.

The audiometric thresholds at each frequency were analyzed by gender and age group (Tab. 2). Due to missing
Table 1. Characteristics of participants who completed audiometric tests $(\mathrm{N}=2027)$

\begin{tabular}{|c|c|c|}
\hline Characteristic & Number ${ }^{\mathrm{a}}$ & Percent(\%) \\
\hline \multicolumn{3}{|l|}{ Year } \\
\hline 2006 & 957 & 47.2 \\
\hline 2007 & 436 & 21.5 \\
\hline 2008 & 634 & 31.3 \\
\hline \multicolumn{3}{|l|}{ Province } \\
\hline Gyeonggi-do & 248 & 12.2 \\
\hline Gangwon-do & 336 & 16.6 \\
\hline Chungcheongbuk-do & 112 & 5.5 \\
\hline Chungcheongnam-do & 94 & 4.6 \\
\hline Jeollabuk-do & 142 & 7.0 \\
\hline Jeollanam-do & 384 & 18.9 \\
\hline Gyeongsangbuk-do & 277 & 13.7 \\
\hline Gyeongsangnam-do & 434 & 21.4 \\
\hline \multicolumn{3}{|l|}{ Gender } \\
\hline Male & 906 & 44.7 \\
\hline Female & 1121 & 55.3 \\
\hline \multicolumn{3}{|l|}{ Age } \\
\hline $20-29$ & 9 & 4.0 \\
\hline $30-39$ & 75 & 3.7 \\
\hline $40-49$ & 351 & 17.3 \\
\hline $50-59$ & 555 & 27.4 \\
\hline $60-69$ & 644 & 31.8 \\
\hline $70-79$ & 356 & 17.6 \\
\hline $80-89$ & 36 & 1.8 \\
\hline $90-99$ & 1 & 0.0 \\
\hline \multicolumn{3}{|l|}{ Years of farm work } \\
\hline $0-9$ & 259 & 14.0 \\
\hline $10-19$ & 279 & 15.1 \\
\hline $20-29$ & 387 & 20.1 \\
\hline $30-39$ & 344 & 18.6 \\
\hline $40-49$ & 329 & 17.8 \\
\hline $50-59$ & 201 & 10.9 \\
\hline $60-88$ & 48 & 2.6 \\
\hline \multicolumn{3}{|l|}{ Principal farm commodity } \\
\hline Paddy farming & 635 & 35.1 \\
\hline Field farming & 329 & 18.2 \\
\hline Fruit farming & 394 & 21.8 \\
\hline Greenhouse farming & 377 & 20.8 \\
\hline Stockbreeding & 47 & 2.6 \\
\hline Others (special crop, etc.) & 27 & 1.5 \\
\hline \multicolumn{3}{|l|}{ Education level } \\
\hline No institutional education & 326 & 16.2 \\
\hline Elementary school or less & 546 & 27.1 \\
\hline Middle school & 533 & 26.5 \\
\hline High school & 380 & 18.9 \\
\hline Undergraduate school & 179 & 8.9 \\
\hline Graduate school or more & 21 & 1.0 \\
\hline Unknown & 28 & 1.3 \\
\hline \multicolumn{3}{|l|}{ Smoking habit } \\
\hline Nonsmoker & 1255 & 65.1 \\
\hline Ex-smoker & 284 & 14.7 \\
\hline Current smoker & 390 & 20.2 \\
\hline \multicolumn{3}{|l|}{ Alcohol consumption } \\
\hline Yes & 970 & 49.8 \\
\hline No & 977 & 50.2 \\
\hline
\end{tabular}

a180 participants had missing data regarding farm working period, 218 had missing data regarding principal farm commodity, 14 had missing data regarding education level, 98 had missing data regarding smoking habit, and 80 had missing data regarding alcohol consumption.

data, the numbers were different at each frequency. At each frequency, all threshold means were significantly different by age group for each gender.

Hearing impairment in men and women were compared at each frequency. Hearing impairments at $3 \mathrm{kHz}$ and above were more prevalent in men than in women. Prevalence of moderate-to-profound hearing impairment was 19.6\% (363 persons) in the total study population, and increased with age. The prevalence was $1.2 \%$ for individuals in their $30 \mathrm{~s}$, $8.0 \%$ in their $40 \mathrm{~s}, 11.9 \%$ in their $50 \mathrm{~s}, 22.9 \%$ in their $60 \mathrm{~s}$, $40.7 \%$ in their $70 \mathrm{~s}$, and $60.7 \%$ for individuals in their $80 \mathrm{~s}$ 
Table 2. Comparison of results of pure-tone audiometry at each frequency between men and women.

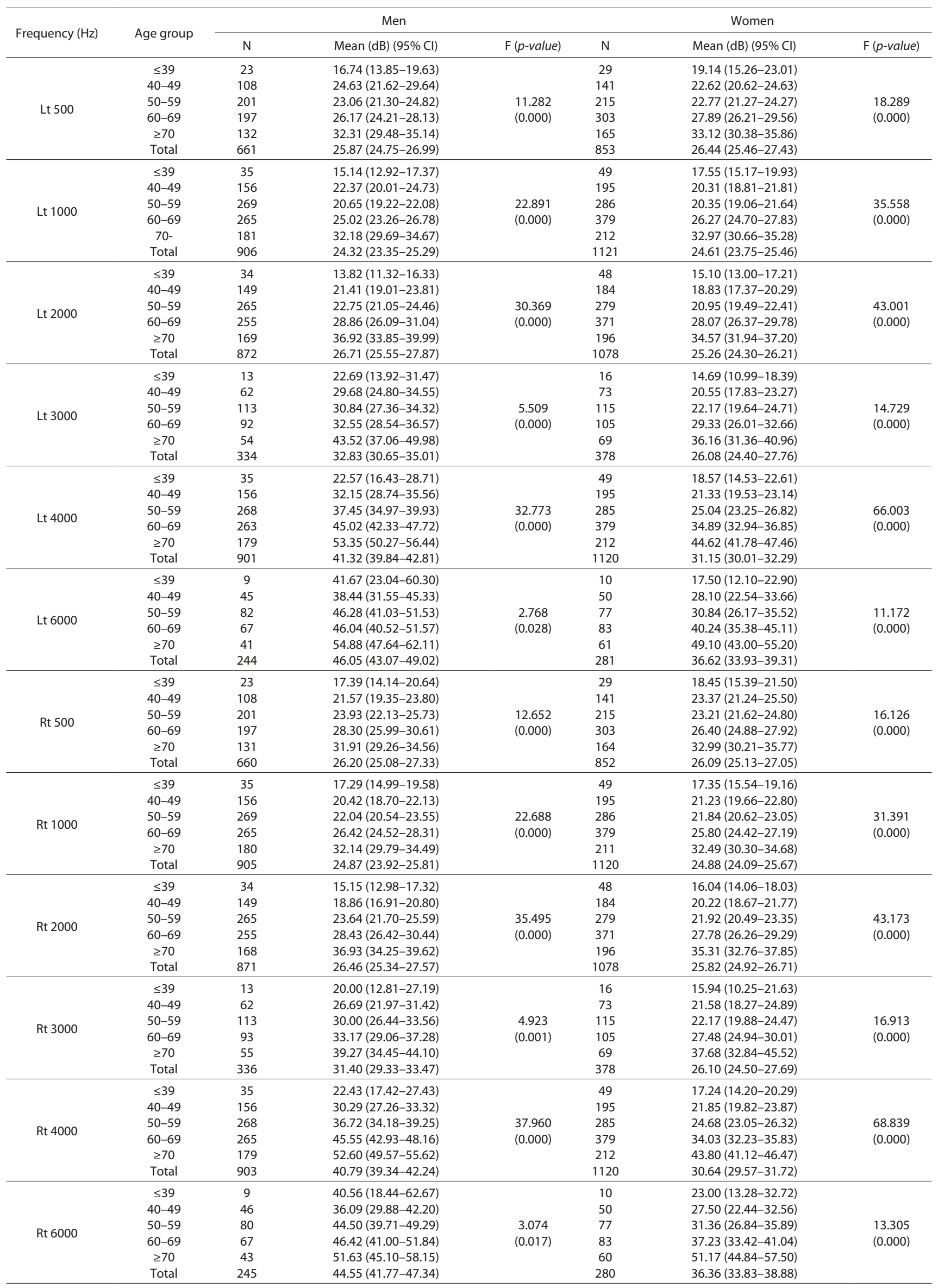


Table 3. Prevalence of moderate-to-profound hearing impairment across age groups.

\begin{tabular}{|c|c|c|c|c|c|c|c|c|}
\hline & \multicolumn{3}{|c|}{ Men } & \multicolumn{3}{|c|}{ Women } & \multirow{2}{*}{$\begin{array}{c}\text { Total } \\
\text { Total } \\
(\%)\end{array}$} \\
\hline & & $\begin{array}{l}\text { Left } \\
(\%)\end{array}$ & $\begin{array}{l}\text { Right } \\
(\%)\end{array}$ & $\begin{array}{c}\text { Total } \\
(\%)\end{array}$ & Left (\%) & $\begin{array}{l}\text { Right } \\
(\%)\end{array}$ & $\begin{array}{c}\text { Total } \\
(\%)\end{array}$ & \\
\hline \multirow{6}{*}{$\begin{array}{l}\text { Age } \\
\text { (years) }\end{array}$} & $\leq 39$ & 0.0 & 0.0 & 0.0 & 2.1 & 0.0 & 2.1 & 1.2 \\
\hline & $40-49$ & 9.4 & 5.3 & 11.6 & 2.6 & 4.1 & 5.2 & 8.0 \\
\hline & $50-59$ & 9.5 & 12.4 & 16.7 & 5.0 & 5.7 & 7.6 & 11.9 \\
\hline & $60-69$ & 17.0 & 19.2 & 25.0 & 15.4 & 13.1 & 21.6 & 22.9 \\
\hline & $\geq 70$ & 37.2 & 32.7 & 46.4 & 31.7 & 28.4 & 39.4 & 42.4 \\
\hline & $\begin{array}{c}x^{2} \\
(p \text {-value })\end{array}$ & $\begin{array}{l}67.605 \\
(0.000)\end{array}$ & $\begin{array}{l}54.033 \\
(0.000)\end{array}$ & $\begin{array}{l}71.093 \\
(0.000)\end{array}$ & $\begin{array}{l}101.662 \\
(0.000)\end{array}$ & $\begin{array}{l}80.882 \\
(0.000)\end{array}$ & $\begin{array}{c}114.519 \\
(0.000)\end{array}$ & \\
\hline
\end{tabular}

Table 4. Differences in mean age and years of farm work between the normal hearing group and moderate-to-profound hearing impairment group.

\begin{tabular}{lcccccc}
\hline & $\begin{array}{c}\text { Hearing } \\
\text { ability }\end{array}$ & Number & Mean & $\begin{array}{c}\text { Standard } \\
\text { Deviation }\end{array}$ & $t$ & p-value \\
\hline Age & Normal & 1493 & 56.87 & 10.799 & -15.490 & 0.000 \\
\hline Years of & Normal & 1356 & 27.69 & 15.896 & -8.640 & 0.000 \\
farm work & Impaired & 328 & 36.21 & 16.531 & & \\
\hline
\end{tabular}

Table 5. Differences in farm commodities between the normal hearing group and moderate-to-profound hearing impairment group.

\begin{tabular}{llccccccccc}
\hline & & \multicolumn{7}{c}{ Principal farm commodity* } & Total \\
\cline { 3 - 9 } & & $\mathbf{1}$ & $\mathbf{2}$ & $\mathbf{3}$ & $\mathbf{4}$ & $\mathbf{5}$ & $\mathbf{6}$ & $\mathbf{7}$ & \\
\hline \multirow{2}{*}{ Normal } & Number & 501 & 264 & 309 & 324 & 40 & 18 & 3 & 1459 \\
& $(\%)$ & $(78.9)$ & $(80.2)$ & $(78.4)$ & $(85.9)$ & $(85.1)$ & $(75.0)$ & $(100.0)$ & $(80.7)$ \\
\hline \multirow{2}{*}{ Impaired } & Number & 134 & 65 & 85 & 53 & 7 & 6 & 0 & 350 \\
& $(\%)$ & $(21.1)$ & $(19.8)$ & $(21.6)$ & $(14.1)$ & $(14.9)$ & $(25.0)$ & $(0.0)$ & $(19.3)$ \\
\hline \multirow{2}{*}{ Total } & Number & 635 & 329 & 394 & 377 & 47 & 24 & 3 & 1809 \\
\hline
\end{tabular}

* 1 - Paddy farming; 2 - Field farming; 3 - Fruit farming; 4 - Greenhouse farming; 5 Stockbreeding; 6 - Special crop farming; 7 - Others.

and older. These rates were significantly different from one another. When the prevalence was divided of moderate-toprofound hearing impairment by gender and side of the head, the increasing trend of prevalence with age was maintained (Tab. 3).

There were significant differences in mean age and years of farm work between the normal hearing and the moderateto-profound hearing impairment groups (Tab. 4).

There was no significant difference $(\chi 2=11.107 ; \mathrm{p}=0.085)$ in farm commodities between the normal and moderate-toprofound hearing impairment groups (Tab. 5).

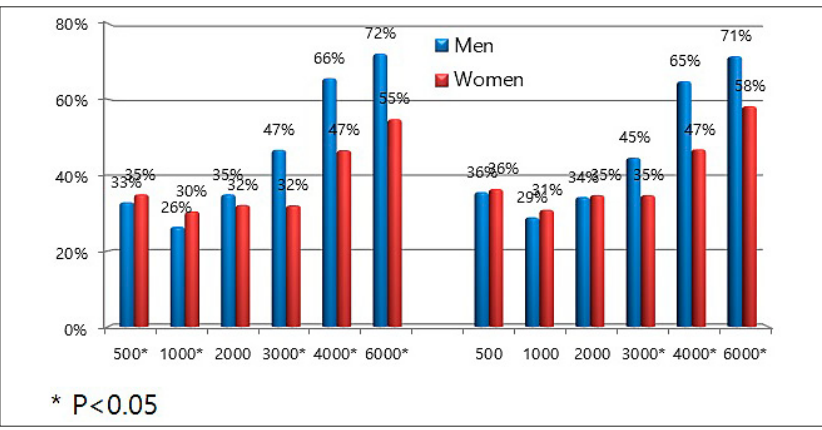

Figure 1. The prevalence of hearing impairment of left and right ears

\section{DISCUSSION}

This study is the first to evaluate hearing impairment in Korean farmers nationwide. There have been few studies that have performed audiometric testing to measure hearing impairment at the national level in Korea [12]. In the Korean National Health and Nutrition Examination Survey (KNHANES), Korean adults completed audiometric testing (2010-2012, 16,040 persons). The weighted prevalence of mild hearing impairment (unaided pure tone audiometric threshold of 26-40dB for the superior ear) in Korean adults was $20.5 \%$, and that of moderate-to-profound hearing impairment (unaided pure tone audiometric threshold of $40 \mathrm{~dB}$ for the superior ear) $-9.2 \%[12]$.

In addition, men's hearing test results of this study were compared with those of KNHANES of 2013 [13]. The mean hearing thresholds at $4 \mathrm{kHz}$ were higher for farmers than the general population aged 40-59. Furthermore, there was a difference in hearing threshold interval by age. In the $40 \mathrm{~s}$, the difference of mean hearing thresholds at $4 \mathrm{kHz}$ was $8.35 \mathrm{~dB}$, in the $50 \mathrm{~s}-0.7 \mathrm{~dB}$. On the other hand, at over 60 -years-old, the mean hearing threshold was worse in the general population than in farmers. This shows that the high prevalence of hearing loss of farmers is not due to presbycusis. Rather, the hearing loss of farmers at a young age is problematic. There were similar studies in other countries, e.g. in Australia, it has been reported that farmers have an average hearing threshold similar to that of the general population aged 10-15 years older [14]. In addition, one-fifth of the patients in a New Zealand study had a $4000 \mathrm{~Hz}$ notch using the Occupational Safety and Health(OSH) 2002a criteria[15]. Despite differences in the definitions of hearing impairment and methods of measurement, the prevalence rate of hearing impairment in this study is higher than that of the general population in Korea.

In the general population, hearing impairment, after hypertension and arthritis, is one of the most highly prevalent chronic diseases [16]. The prevalence of hearing impairment in the United States is predicted to increase significantly due to an aging society and the growing use of personal hearing aids [17]. There are many causes of hearing loss, including genetic predisposition, maternal disease, complications at birth, aging, infectious diseases, such as meningitis or chronic ear infections, use of ototoxic drugs, or exposure to excessive noise [12]. Old age is the most common cause of hearing loss [18]. After adjusting for age, male gender, occupational exposure, and lower levels of education, were associated with the incidence of hearing loss[19].

In a previous study, the prevalence of mild hearing impairment (unaided pure tone audiometric threshold of 26$40 \mathrm{~dB}$ for the superior ear) of low/mid frequencies (averaged pure tone thresholds measured at $0.5,1.0$, and $2.0 \mathrm{kHz}$ for each ear) in women was high, compared with that in men $(18.3 \%$ vs. $15.7 \%, \mathrm{p}<0.001)$. In contrast, a higher prevalence of high-frequency mild hearing impairment was seen in men [12]. In the current study, the results of hearing impairment testing showed the same tendency. Men tend to experience more occupational noise exposure, which affects hearing impairment, especially at high frequency. Men also have more high-frequency mild hearing impairment [12]. There may be extrinsic factors contributing to hearing impairment in men. Most Korean men have to serve in the military for at least 21 months, and that experience could cause 
NIHL and tinnitus [20]. There are arguments that the high prevalence of hearing impairment among men, especially at high frequencies, may be due to genetic vulnerability or differences in noise exposure. However, the reasons behind this difference remain unclear.

Noise exposure levels from riding a motorbike; driving a tractor, bulldozer, truck, or other heavy machinery, and using hand power tools were above the workplace exposure standard for farmers [15]. The prolonged and cumulative effect of exposure to excessive noise or peak noise of shotguns also causes hearing damage [21]. Farming equipment, such as grain dryers, circular saws, tractors, hand drills, and combines, have noise levels above $85 \mathrm{~dB}$ [22]. In New Zealand, where a personal noise dosimetry was conducted, the mean noise exposure level was $86.6 \mathrm{Db}(\mathrm{A})$ for sheep farmers and $85.7 \mathrm{~dB}(\mathrm{~A})$ for mixed farmers. According to another study, $51 \%$ farmers were exposed to noise greater than $85 \mathrm{~dB}(\mathrm{~A})$, and $18 \%$ were exposed to levels above $90 \mathrm{~dB}(\mathrm{~A})$ [21]. Specifically, the noise levels of farm activities and equipment approximately range from spraying from a tractor $(81 \mathrm{~dB})$ to operating a chain saw (99-119dB) [21]. In addition, one-third of agricultural workers in a previous study were exposed to noise levels above the recommended Australian Standard of $85 \mathrm{~dB}(\mathrm{~A})$ [15].

The studies described above indicate that noise exposure from the use of agricultural machinery can cause hearing loss in farmers. Also in Korea, farmers frequently use equipment such as motor cultivators, tractors, motor sprayers, motor rice-planting machines, combines, and dryers. However, there have been few studies on the noise level on a farm. The presented study did not measure the degree of noise exposure or identify the agricultural machinery used by each person. In the subsequent study, it will necessary to evaluate the degree of hearing loss by the noise sources. The measurement of noise level on a farm is necessary for the preservation of farmers' hearing acuity.

Noise at work can be a risk because it interferes with communication and disrupts one's ability to hear warnings [21]. In a systematic review and meta-analysis, the pooled odds ratio of agricultural injury was 2.01 in farmers with hearing loss or hearing aid devices [23]. In a case-control series of Iowa farmers in the USA, wearing a hearing aid increased animal-related injuries $(\mathrm{OR}=5.35)$, machineryrelated injuries $(\mathrm{OR}=4.37)$, and total agricultural injuries $(\mathrm{OR}=2.36)[24]$. Moreover, individuals who had moderate-toprofound hearing loss had impaired health-related quality of life after adjusting for age, gender, education, arthritis, other chronic diseases, and poor visual acuity[25].

In the United States, agricultural employers are not subject to the US Department of Labor Occupational Safety and Health Administration's (OSHA) noise standards [5]. In addition, it is difficult for farmers to access safety specialists, industrial hygienists, or occupational health nurses [4]. The absence of accessibility to a health care system is similar in Korea. It is necessary to protect farmers' health, particularly if they do not use protective equipment.

There are several limitations in the current study. First, when performing an audiometric examination, a soundproof booth was not used, nor was noise level measured in the rooms where hearing tests were performed. According to a previous study [26], background noise can significantly disturb the accuracy of hearing threshold at the lower frequencies of 500 and $1,000 \mathrm{~Hz}$. Specifically, when audiometric tests were conducted in both non-compliant and compliant rooms, the result differences at 500, 1,000 and 2,000 Hz ranged 30-32 dB. The other frequencies of 2,000-4000, 6,000 and $8,000 \mathrm{~Hz}$ showed no statistically significant differences. Therefore, not controlling the noise of the measuring room might not have a significant impact on the evaluation of the moderate-to-profound hearing impairment. Furthermore, Occupational Safety and Health Administration OSHA) requires that the audiometric test rooms, which can be open, should not have background sound pressure levels exceeding the maximum permissible ambient noise levels (MPANL), which are $40 \mathrm{~dB}$ SPL at $500 \mathrm{~Hz}, 40 \mathrm{~dB}$ SPL at $1000 \mathrm{~Hz}, 47 \mathrm{~dB}$ $\mathrm{SPL}$ at $2000 \mathrm{~Hz}, 57 \mathrm{~dB}$ SPL at $4000 \mathrm{~Hz}$, and $62 \mathrm{~dB}$ SPL at $8000 \mathrm{~Hz}$ [27]. $40 \mathrm{~dB}$ is the average decibel rating for a library and a quiet house in daytime, and $50 \mathrm{~dB}$ the average decibel rating in a quiet office. The hearing tests in the presented study were performed in a quiet house located in secluded countryside, in order not exceed the L.

In addition, no physical examinations or bone-conduction threshold tests were perform; therefore, underlying ear diseases, such as otitis media, could have been missed. For more accurate diagnosis of noise-induced hearing loss, airway and bone conduction tests are required. However, a one-on-one interview was conducted to investigate detailed past illnesses and exclude patients who had a previous history of ear diseases, such as otitis media, trauma to the eardrum, etc., which could cause conductive hearing, and tried to include only sensorineural hearing loss in the analysis. Additional studies need to evaluate both the air and bone conduction to accurately evaluate the noise-induced hearing loss. Because of measurement differences, comparison of the obtained results with those of other studies should be conducted with caution.

Second, there are missing data which could affect the results. In particular, not all participants had audiometric data at all frequencies, there is therefore some risk of miscalculation of the prevalence of hearing impairment. Third, it was not possible to assess potentially confounding factors, aside from age and years of farm work. In future studies, evaluation of noise exposure to agricultural implements and measurement of surrounding noise for each farmer should be conducted.

\section{CONCLUSIONS}

The study shows that the prevalence of hearing impairment in Korean farmer is $19.6 \%$, higher than that of the general population. A probable reason for this difference is excessive noise exposure on farms. To manage farmers' hearing health, precise evaluations of farmers' hearing acuity and noise exposure at farms should be conducted. This study might be a stepping-stone to protecting the hearing health of farmers.

\section{REFERENCES}

1. Fuchs A, Kouimintzis D, Neumann G, Kirch W. Health risks related to crop farming in Europe. J Public Health (Bangkok) 2007; 15: 233-44. doi:10.1007/s10389-007-0131-3.

2. Voaklander DC, Umbarger-Mackey ML, Wilson ML. Health, Medication Use, and Agricultural Injury: A Review. Am J Ind Med. 2009; 52: 876-89. doi:10.1002/ajim.20749.

3. Lee SJ, Kim I, Ryou H, Lee KS, Kwon YJ. Work-related injuries and fatalities among farmers in South Korea. Am J Ind Med. 2012; 55: 76-83. doi:10.1002/ajim.21016. 
4. McCullagh M, Robertson C. Too Late Smart. AAOHN J. 2009; 57: 99-105. doi:10.3928/08910162-20090301-06.

5. Ikhizama BO, Lawal BO. Women scientists' involvement in agricultural development in Southwest Nigeria. J Agric Food Inf 2006; 7: 11-22. doi:10.1300/J108v07n04.

6. Hwang SA, Gomez MI, Sobotova L, Stark AD, May JJ, Hallman EM. Predictors of hearing loss in New York farmers. Am J Ind Med. 2001; 40: 23-31. doi:10.1002/ajim.1068.

7. Renick KM, Crawford J Mac, Wilkins JR. Hearing loss among ohio farm youth: A comparison to a national sample. Am J Ind Med. 2009; 52: 233-9. doi:10.1002/ajim.20668.

8. Dobie RA. The burdens of age-related and occupational noise-induced hearing loss in the United States. Ear Hear. 2008; 29: 565-77. doi:10.1097/ AUD.0b013e31817349ec.

9. Lie A, Skogstad M, Johnsen TS, Engdahl B, Tambs K. The prevalence of notched audiograms in a cross-sectional study of 12,055 railway workers. Ear Hear. 2004; 36: e86-92. doi:10.1097/AUD.0000000000000129.

10. Kurmis A, Apps S. Occupationally-Acquired Noise-Induced Hearing Loss: A Senseless Workplace Hazard. Int J Occup Med Environ Health 2007;20:127-36. doi:10.2478/v10001-007-0016-2.

11. Kim KS. Occupational hearing loss in Korea. J Korean Med Sci. 2010; 25: 62-9. doi:10.3346/jkms.2010.25.S.S62.

12. Hong JW, Jeon JH, Ku CR, Noh JH, Yoo HJ, Kim D-J. The Prevalence and Factors Associated with Hearing Impairment in the Korean Adults: The 2010-2012 Korea National Health and Nutrition Examination Survey (Observational Study). Medicine (Baltimore) 2015; 94: e611. doi:10.1097/MD.0000000000000611.

13. Korea Centers for Disease Control and Prevention. Korea National Health and Nutrition Examination Survey(KNHANES) n.d. https:// knhanes.cdc.go.kr/knhanes/sub03/sub03_01.do (access: 2018.12.17).

14. Depczynski J, Challinor K, Fragar L. Changes in the hearing status and noise injury prevention practices of Australian farmers from 1994 to 2008. J Agromedicine 2011; 16: 127-42. doi:10.1080/105992 4X.2011.554770

15. Firth H, Herbison P, Mc Bride D. Dust and noise exposures among farmers in Southland,New Zealand. Int J Env Heal Res. 2006; 16: 155-61. doi:10.1080/09603120500538267.
16. Mares-perlman JA, Nondahl DM. Prevalence of Hearing Loss in Older Adults in Beaver Dam, Wisconsin 1998; 148: 879-86.

17. Agrawal Y, Platz E a, Niparko JK. Prevalence of Hearing Loss and Differences by Demographic Characteristics Among US Adults. Arch Intern Med. 2008; 168: 1522-30. doi:10.1001/archinte.168.14.1522.

18. Review S. CLINICIAN' S CORNER Screening and Management of Adult Hearing Loss in Primary Care Scientific Review 2011; 289: 1976-85.

19. Cruickshanks KJ, Tweed TS, Wiley TL, Klein BEK, Klein R, Chappell $\mathrm{R}$, et al. The 5-year incidence and progression of hearing loss: the epidemiology of hearing loss study. Arch Otolaryngol Head Neck Surg. 2003; 129: 1041-6. doi:10.1001/archotol.129.10.1041.

20. Bahng J, Lee J. Hearing Thresholds for a Geriatric Population Composed of Korean Males and Females 2015; 19: 91-6.

21. Williams W, Brumby S, Calvano A, Hatherell T, Mason H, MercerGrant C, et al. Farmers' work-day noise exposure. Aust J Rural Health 2015; 23: 67-73. doi:10.1111/ajr.12153.

22. Coleman BM. Dangerous Noise Levels Leave Farmers at Risk for Hearing Loss 2012: 2012.

23. Jadhav R, Achutan C, Haynatzki G, Rajaram S, Rautiainen R. Risk Factors for Agricultural Injury: A Systematic Review and Meta-analysis. J Agromed. 2015; 20: 434-49. doi:10.1080/1059924X.2015.1075450.

24. Choi SW, Peek-Asa C, Sprince NL, Rautiainen RH, Donham KJ, Flamme GA, et al. Hearing loss as a risk factor for agricultural injuries. Am J Ind Med. 2005; 48: 293-301. doi:10.1002/ajim.20214.

25. Dalton DS, Cruickshanks KJ, Klein BEK, Klein R, Wiley TL, Nondahl DM. The impact of hearing loss on quality of life in older adults. Gerontologist 2003; 43: 661-8. doi:10.1093/geront/43.5.661.

26. Carien Weyers L de J. The influence of the audiometric test environment on screening audiometry results. Audiometers - Part 1 Pure-Tone Audiometers. IEC, 1992.

27. Occupational Safety and Health Administration, United States. https://www.osha.gov/laws-regs/regulations/ standardnumber/1910/1910.95AppD (access: 2018.12.17). 